\title{
A DIGNIDADE NA OBRA DE JEREMY WALDRON
}

\author{
Claudia Perrone ${ }^{1}$ \\ José Guilherme Giacomuzzi ${ }^{2}$
}

\section{Resumo}

O artigo expõe as principais ideias do filósofo político e teórico do direito Jeremy Waldron sobre a "dignidade", ideia central ao tema dos direitos humanos. $\mathrm{O}$ artigo é dividido em três itens: no primeiro é abordada a dignidade como um status jurídico, a qual remete às noções de posição (rank) e função (role); no segundo é estudada a dignidade como fundamento de direitos; e no terceiro, subdividido em duas partes, são abordadas as formas como o direito protege a dignidade e, depois, a eventual insuficiência dessa proteção. Seguem considerações finais.

Palavras-Chave: Jeremy Waldron. Dignidade. Direitos Humanos.

\section{INTRODUÇÃO}

Muitos filósofos tratam o tema da "dignidade humana” com certo desdém (WALDRON, 2014, p.01). Uma exceção digna de nota é o filósofo político e teórico do direito Jeremy Waldron, Professor nas Universidades de Nova Iorque e Oxford, certamente um dos mais influentes scholars no mundo jurídico-político hoje.

Na última década, Waldron tem lançado luz sobre o tema por meio de inúmeros artigos. Dadas:

1. A centralidade da dignidade tanto nas cartas internacionais sobre Direitos Humanos quanto nos sistemas jurídicos internos, o Brasil inclusive, ${ }^{3} \mathrm{e}$

\footnotetext{
${ }^{1}$ Mestranda em Direitos Humanos, UniRitter, Porto Alegre, RS. Advogada especialista em Direito Empresarial (Unisinos, 2010). E-mail: cperrone06@gmail.com

${ }^{2}$ Doutor em Direito (George Washington University Law School, EUA, 2007). Professor Adjunto de Direito Administrativo na Faculdade de Direito da UFRGS e Professor no curso de Direito (graduação e mestrado em Direitos Humanos) do UniRitter, campus Porto Alegre, RS. E-mail: jose.giacomuzzi@ufrgs.br

${ }^{3}$ Com o advento da Declaração Universal dos Direitos Humanos, houve o reconhecimento tanto no preâmbulo da “[...] dignidade inerente a todos os membros da família humana [...]", quanto no artigo $1^{\circ}$, de que "Todos os seres humanos nascem livres e iguais em dignidade e direitos". A partir disso, outros documentos internacionais também passaram a distinguir a importância da dignidade, tais como: a Convenção Americana de Direitos Humanos; o Pacto Internacional sobre direitos Civis e Políticos; o Pacto Internacional sobre Direitos Econômicos, Sociais e Culturais; e a Convenção Internacional sobre os Direitos da Pessoa com Deficiência. No âmbito interno, como exemplo, podemos mencionar a Constituição Federal de 1988, que estabelece a dignidade da pessoa humana como um fundamento da República brasileira e a Lei Fundamental Alemã, que considera a dignidade da pessoa humana intangível, estabelecendo, ainda, o dever do poder público de respeitá-la e protegê-la.
} 


\section{Quaestio Iuris}

2. A inegável proeminência dos argumentos de Waldron no cenário intelectual, escrevemos este breve estudo com objetivo de sistematizar, tão concisamente quanto possível, as ideias e argumentos de Waldron sobre a "dignidade". ${ }^{4}$

Salvo nas breves considerações finais, o presente ensaio é predominantemente descritivo, e a bibliografia utilizada, com raras exceções, limita-se propositadamente aos trabalhos específicos do autor examinado.

Dividimos o estudo em três itens, agrupando-os por linha argumentativa. Assim, no primeiro item abordaremos a concepção que o Autor constrói a partir do significado da dignidade, considerada como um status jurídico que remete às noções de posição (rank) e função (role); no segundo item exporemos a visão de Waldron sobre a dignidade como fundamento de direitos; e no terceiro item, subdividido em duas partes, abordaremos primeiro a proteção da dignidade pelo direito, identificando a dignidade inerente ao sistema jurídico, e depois apresentaremos a possibilidade de que esta proteção fique aquém do almejado.

\section{A DIGNIDADE A PARTIR DE SEUS USOS: POSIÇÃO (RANK) E FUNÇÃO (ROLE)}

Em abril de 2009, Jeremy Waldron foi o scholar convidado a proferir as afamadas Tanner Lectures na Universidade de Berkeley, Califórnia. O tema foi intitulado Dignity, Rights, and Rank, ${ }^{5}$ e desde então Waldron vem desenvolvendo suas ideias sobre a dignidade em inúmeros escritos.

Waldron inicia as Tanner Lectures afirmando um truísmo para depois sugerir algo insólito: o truísmo é o de que a dignidade pode ser considerada tanto como um princípio da moralidade, quanto um princípio do Direito. A sugestão insólita é a de que, embora reconhecendo que seria mais natural analisar primeiro o aspecto moral da dignidade, Waldron propõe-se o contrário: lançar luz sobre o conceito moral de dignidade a partir de uma abordagem teórico-jurídica.

Por meio da Teoria do Direito, a dignidade pode ser analisada, diz Waldron (2012a, p.12-3), como um princípio com funções fundamentais e explicativas, lançando, assim, alguma luz (jurídica) sobre sua utilização no discurso moral. A premissa do Autor é que a dignidade está histórica e intimamente conectada com a ideia de direitos subjetivos (rights), de modo que, para compreender a dignidade, é necessário considerá-la primeiro como uma ideia jurídica, verificando seu funcionamento no ambiente do Direito, o qual é estruturalmente diferente do ambiente da moralidade.

\footnotetext{
${ }^{4}$ Isso implica que (i) as ideias aqui são de Waldron e (ii) muitas passagens deste texto são em verdade paráfrases dos escritos de Waldron. Nos poucos casos em que as ideias são dos autores deste texto, isso fica explícito no texto.

${ }^{5}$ As conferências podem ser ouvidas e/ou lidas on line: http://tannerlectures.berkeley.edu/2008-2009/. Acesso em 13.abr.2015. Waldron publicara artigo em 2007 intitulado Dignity and Rank, mas modificou em vários pontos sua posição para as Berkeley Tanner Lectures, pelo que o artigo de 2007 não será analisado aqui. As Berkeley Tanner Lectures (e os comentários críticos que a seguiram no evento, de Michael Rosen, Wai Chee Dimock e Don Herzog) foram publicadas em 2012 em livro. Ver WALDRON, Jeremy. Dignity, Rights, and Rank (Berkeley Tanner Lectures). Oxford University Press, 2012.
} 
Parece não haver no direito, afirma Waldron, qualquer definição canônica de "dignidade", a qual parece mais "intuitiva" e muitas vezes confusa. ${ }^{6}$ No entanto, mesmo quando utilizada como um recurso aparentemente retórico ou político -- por exemplo, como fundamento de direitos no preâmbulo de Pactos Internacionais ou Constituições -- a dignidade não deve, segundo Waldron, ser tratada como ideia meramente moral. Também não se pode presumir, diz o Autor, que o sentido da dignidade somente possa ser encontrado na filosofia moral.

Aqui pensamos que há algo crucial: o Direito, diz (o que neste ponto é reveladoramente positivista) Jeremy Waldron (2012a, p.14-5), contém, envolve e constitui seus próprios fundamentos, e não somente os toma emprestados da moral. Pode ser, diz Waldron, que a dignidade no âmbito da moral seja diferente da dignidade no âmbito do direito. Daí que o significado jurídico da dignidade deve ser construído a partir da Teoria do Direito e da Filosofia Jurídica. Essa é a construção proposta por Waldron. ${ }^{7}$

Segundo Waldron (2013a, p.01), as teorias da dignidade têm sido elaboradas a partir de duas concepções que, aparentemente, são bastante distintas:

i. Uma antiga ideia de dignidade, elaborada no mesmo sentido da dignitas romana, relacionada com o status do exercício de uma "função" (role) ou de uma "posição" (rank) hierarquicamente ligada à nobreza;

ii. Uma ideia igualitária moderna de dignidade humana, a qual seria inalienável e entendida como investida em toda pessoa humana, relacionando-se com a humanidade enquanto tal, independentemente da posição ou função do indivíduo ou das ações ou acontecimentos de sua vida. As relações entre essas duas concepções, diz Waldron, são apresentadas no mais das vezes de uma dessas duas maneiras:

iii. Ou a partir de uma história sobre a concepção da dignidade humana substituindo a concepção da dignitas após um longo período de uma difíil coexistência entre elas;

iv. Ou a partir de uma história sobre a transformação da concepção dignitas em uma concepção mais igualitária, uma história que não envolve um corte na conexão entre dignidade e posição, mas envolve um tipo de universalização da nobreza para todos.

Waldron (2011, p.1118-20) refere que a relação entre dignidade e posição pode parecer uma ideia pouco promissora para o discurso dos direitos humanos, especialmente quando se pretende (como parece intuitivo sob uma perspectiva igualitária) a negação de que humanos tenham e/ou estejam em posições que os

\footnotetext{
${ }^{6}$ Waldron cita a lição de Oscar Schachter, em conhecido artigo da década de 1980 (ver SCHACHTER, Oscar. Human Dignity as a Normative Concept. American Journal of International Law. v. 77, p. 848-854, 1983).

${ }^{7}$ Essa opção metodológica foi abertamente criticada Michael Rosen, um dos comentadores das Berkeley Tanner Lectures. Aqui não é o espaço para expor a posição de Rosen. O leitor pode ouvir o debate no endereço indicado na nota 5 e pode encontrar o texto de Rosen em http://scholar.harvard.edu/michaelrosen/publications/replies-jeremy-waldron (acesso em 14.abr.2015), além de lê-lo nas pp. 79-98 do livro: WALDRON, Jeremy. Dignity, Rights, and Rank (Berkeley Tanner Lectures). Oxford University Press, 2012.
} 


\section{Quaestio Iuris}

distinguem quanto ao valor. E mesmo que essa perspectiva igualitária tenha levado alguns teóricos a substituir a antiga equação dignidade/posição por uma concepção de dignidade alternativa (como uma noção judaico-cristã de dignidade), Waldron não a adotada. Para ele, a noção geral da dignidade associou-se à de que os humanos são uma espécie dotada de uma posição superior (high-ranking), chamados a uma vocação especial no mundo. Essa posição lhes atribui certa nobreza ou realeza e, ao invés de simplesmente ser repudiada, deveria ser generalizada, colocando todos os seres humanos em uma posição de status superior. A concepção de Waldron pretende, portanto, uma elevação do status de todos os seres humanos; é uma tentativa de conceder a todo ser humano algo de dignidade e de expectativa de respeito que antigamente era concedida apenas à nobreza. A imagem proposta por ele é de uma sociedade de apenas uma casta -- e uma casta superior -- onde todos os humanos são equiparados a brâmanes:

Todo homem um duque, toda mulher uma rainha, todos titulares de uma espécie de deferência e consideração, a pessoa e o corpo de todos sacrossanto, na forma que os nobres tinham direito a deferência ou na forma que um ataque sobre o corpo ou a pessoa de um rei era considerado um sacrilégio. (WALDRON, 2012a, p. 34).

Assim, para Waldron (2012a, p.21), tratar a dignidade humana como um valor de grande importância não significa, necessariamente, considerá-la como o valor mais importante, ou mais elevado. A importância atribuída pode remeter a essa ideia de status, onde a posição (rank) expressa coisas como a autoridade, o respeito e a deferência, não com peso meramente moral, mas com a ideia de um status jurídico superior e do direito aos tratamentos reservados, respectivamente, à realeza ou à nobreza; tratamentos diametralmente diversos daqueles reservados aos status inferiores, como o de escravidão ou servidão.

No caso da dignidade no sentido de uma função ou ofício, sustenta Waldron (2011, p.1120-1), a importância atribuída ao status está associada à ideia da responsabilidade inerente ao seu exercício. Nesse caso, as funções cívicas exercidas pelo indivíduo são mais importantes do que sua posição hierárquica de nascimento, porquanto é a realização de tal função ou ofício que lhe concede direito a um tratamento de deferência e respeito. O exemplo do Autor é o da dignidade de Júlio César como o mais importante dos cidadãos da Roma antiga; esta dignidade não estava associada à sua nobreza de nascimento, mas sim às suas funções cívicas, i.e, ser ele um general e, por um período, pontifex maximus. ${ }^{8}$

Waldron (2012a, p.34-56) constrói sua concepção de dignidade humana agrupando todas essas ideias, i.e., tanto a ideia antiga da dignidade, ligada à posição hierárquica (rank) ou função/ofício (role) reconhecidamente digno, quanto a noção moderna de igualdade, de uma sociedade onde todos os cidadãos são igualmente tratados como nobres, ou seja, onde há interdependência entre dignidade e igualdade. Para Waldron

\footnotetext{
${ }^{8}$ Também são exemplos do Autor: a dignidade dos embaixadores, associada à sua função como representante de uma nação, assim como a função geral de diplomacia; a dignidade do juiz em relação às importantes tarefas que precisam ser realizadas pelo judiciário; e a dignidade do clérigo no sentido da responsabilidade pela administração da diocese (WALDRON, 2011, p.1120-1). vol. 08, nº. 04, Número Especial. Rio de Janeiro, 2015. pp. 2341-2360 
algumas situações evidenciam a possibilidade de utilizar a concepção antiga de dignidade para lançar alguma luz sobre a concepção moderna de dignidade nos direitos humanos. $\mathrm{O}$ antigo provérbio "a casa de um homem é seu castelo", por exemplo, seria uma manifestação da noção de elevação (leveling-up) de todos os seres humanos (não só dos nobres) à posição superior, refletindo uma ideia de generalização dessa posição. Com o exemplo do Autor é possível relacionar o que antigamente era apenas direito dos nobres (e em relação a seus castelos), ao direito à inviolabilidade de domicílio: "A modéstia de nossas habitações não significa que o direito de privacidade ou segurança contra a invasão, busca ou apreensão [em nosso domicílio] seja menos importante". (WALDRON, 2012a, p.34).

Waldron (2012a, p.55-7; 2012b, p.213-4) apresenta um exemplo histórico, ocorrido em Londres em 1606, que bem revela a noção de generalização da posição ou função superior: um credor da Condessa de Rutland mandou seus homens para que a prendessem pelo não pagamento de uma dívida, tendo a Condessa permanecido em cárcere até o seu efetivo pagamento. Contudo, em julgamento posterior, o credor foi condenado pela prisão indevida da Condessa, por entender que uma nobre somente poderia ser julgada por seus pares e que sua nobreza lhe atribuía uma presunção de riqueza que não autorizava a prisão de seu corpo como garantia de pagamento da dívida, o que se admitia, por exemplo, no caso de um plebeu. Contemporaneamente essa regra é aplicada a todos os devedores: ninguém pode ser detido ou preso por dívida. Noutras palavras, ao dar a plebeus o direito de receber tratamento que antes era confiado exclusivamente a indivíduos de status mais elevado (nobres), o que fazemos é dignificar os plebeus, levantando o seu status.

Cabe esclarecer, aqui, que a expressão status para Waldron (2013b, p.24-5) nada mais é do que uma conveniência expositiva, ou seja, uma expressão abreviada que possui um conteúdo subjacente muito amplo. Exemplificativamente, Waldron (2012a, p.57-61) faz referência à existência de dois tipos de status: o statuscondição (condition status) e o status-classe (sortal status). Ambos expressam status jurídicos; no entanto, o status-condição incorpora consequências jurídicas relativas a estágios da vida humana (e.g. incapacidade absoluta ou relativa), a situações voluntariamente escolhidas (e.g. casamento ou serviço militar), a alguma vicissitude da humanidade (e.g. loucura ou insanidade), além de outras situações da vida ordinária (e.g. falência). Estes status não dizem nada sobre a o indivíduo especificamente, mas representam condições nas quais qualquer um pode estar, estabelecendo as consequências jurídicas para aquela situação. $\mathrm{O}$ status-condição pode ser contrastado com o status-classe, que categoriza os sujeitos jurídicos com base na "classe" de pessoa que são (e.g. escravos). Statusclasse representa a situação e o destino permanente para a pessoa conforme o interesse do Direito; não é adquirido ou perdido conforme suas ações, circunstâncias ou vicissitudes, expressando uma ideia bastante simples: existiriam aqui diferentes classes de pessoas. Para Waldron, é exatamente isso que o princípio da dignidade humana nega, ou seja, não existem diferentes classes de pessoas humanas. 
É importante, portanto, ter presente que as noções de posição e de função subentendidas no conceito moderno de dignidade humana formulada por Waldron (2013b, p.24) têm como noção subjacente o conceito de status jurídico, o qual compreende um conjunto especial de direitos, poderes, limitações, privilégios, imunidades e sujeições determinadas à pessoa, em virtude da condição ou situação em que ela se encontra. Assim, diz Waldron, ao invés de descrevermos todas as circunstâncias e as consequências jurídicas desta condição, resumimos a informação e conseguimos tanto expressar, quanto compreender, os significados técnicos e jurídicos que estão por trás de termos específicos, o que permite conhecer os detalhes da posição jurídica que as pessoas com esse status se encontra.

Para demonstrar que o status não é apenas um rol arbitrário de direitos, poderes, limitações, privilégios, imunidades e sujeições, mas uma lista que faz sentido em relação a alguma ideia subjacente informada no status em questão, Waldron (2013b, p.25-6) utiliza o exemplo do status dos absolutamente ou relativamente incapazes (X). No exemplo, Waldron considera que, se X é menor de dezoito anos, então (i) X tem o direito a receber assistência dos seus pais; e (ii) que $\mathrm{X}$ não tem capacidade civil de celebrar certos contratos etc. Nesse caso, as proposições (i) e (ii) não são proposições jurídicas arbitrárias, mas cada uma delas faz sentido dentro da ideia subjacente de que as crianças têm uma capacidade reduzida de cuidar de si, sendo mais vulneráveis à exploração por terceiros do que aqueles que já atingiram a plena capacidade civil. Todas essas ideias fazem sentido conjuntamente e descrevem uma situação em seu sentido técnico-jurídico. Pensar em um status inclui, portanto, além de uma lista de proposições jurídicas, todas as proposições que, conjuntamente, façam sentido com esse rol de direitos e sejam capazes de expressar uma ideia subjacente sobre a circunstância particular ou vicissitude da condição humana (WALDRON, 2012a, p.57-61).

No entanto, Waldron (2013b, p.01-2) alerta que considerar a dignidade humana como uma posição ou função, no sentido da atribuição de determinado status jurídico a todos os seres humanos está longe de ser uma unanimidade conceitual. No mais das vezes, antes de ser entendida como um status jurídico, a dignidade é vista como fundamento dos direitos (especialmente dos direitos humanos) em um sentido que, como já dito, é facilmente encontrado em preâmbulos de pactos e convenções, assim como na retórica dos muitos estudiosos. Portanto, a construção do conceito de dignidade humana, na forma proposta por Waldron, ou seja, em um sentido que vai além da apresentação de um compromisso político sem rigor filosófico e com pouco significado jurídico, evidencia a necessidade de um exame crítico do papel da dignidade na teoria dos direitos humanos. Esse é o próximo ponto a ser considerado.

\section{A DIGNIDADE COMO FUNDAMENTO DOS DIREITOS HUMANOS}


Em 2009, nas Tanner Lectures em Berkeley, Waldron (2012a, p.17-8) já havia sugerido existir uma dualidade a explorar quanto à dignidade: a possibilidade de pensar a dignidade como (i) fundamento dos direitos humanos e como (ii) conteúdo desses direitos. Esse problema não foi então atacado por Waldron; àquela altura o Autor preferiu insistir que fazia mais sentido dizer que a dignidade é um status jurídico ${ }^{9}$ e que muitos direitos podem ser entendidos como incidentes deste status. No entanto, Waldron já referia que mesmo quando a dignidade fosse tratada como uma posição ou status subsistiria a referida dualidade fundamento/conteúdo, pois ora a dignidade teria caráter de norma geral, estabelecendo uma posição, ora de norma particular, determinando o respeito ou proibindo a degradação dessa posição. ${ }^{10}$

Mas é somente no artigo intitulado "Is Dignity the Foundation of Human Rights?" (2013b), no qual Waldron busca "clarificar o papel da dignidade na teoria dos direitos humanos", é que o Autor escrutina criticamente a tese de que a dignidade seria o fundamento dos direitos humanos.

Já da leitura de documentos internacionais, diz Waldron (2013b, p.02), seria possível notar algumas diferenças na linguagem utilizada acerca da dignidade. Por exemplo, nos Preâmbulos dos Pactos Internacionais sobre Direitos Civis e Políticos e Sobre Direitos Econômicos, Sociais e Culturais consta a frase "esses direitos decorrem da dignidade inerente à pessoa humana" [grifo nosso], a qual parece conter, diz Waldron, algo indubitavelmente fundante. Mas isso não ocorreria na frase "o reconhecimento da dignidade inerente a todos os membros da família humana e de seus direitos iguais e inalienáveis constitui o fundamento da liberdade, da justiça e da paz no mundo" [grifo nosso], a qual, segundo Waldron, apresenta ideia de coordenação, e não de uma (dignidade) com sendo fundante da outra (direitos).

Waldron (2013b, p.02) é consciente de que não se pode colocar muita ênfase na linguagem utilizada em preâmbulos, dado o seu caráter retórico e marcadamente não filosófico. Mas Waldron alerta para o fato de que, se tivermos de desconsiderar a linguagem dos preâmbulos por não estarem de acordo com o que nós pensamos sobre a dignidade, então devemos descartar ambas as passagens, e não uma só delas. Waldron em verdade inicia aqui o seu escrutínio crítico sobre a dignidade como fundamento dos direitos humanos. Como veremos, Waldron discorda dessa visão simplista.

\footnotetext{
${ }^{9} \mathrm{O}$ Autor não pretende descartar a possibilidade de a dignidade ser considerada como fundamento de alguns direitos. Para demonstrar isso, faz a seguinte suposição: se a dignidade for considerada o fundamento de alguns direitos, seu papel quanto às reivindicações específicas deste direito podem ser facilmente reconhecidas (no exemplo, a liberdade de culto e proibição da tortura), mesmo quando a dignidade não é mencionada; mas em relação a outros direitos, por ausência de referência comum, a dignidade pode ser utilizada como o critério daquilo que o direito exige (no exemplo, a ideia de uma remuneração compatível com a dignidade humana não diz exatamente qual é o nível remuneração exigido, mas aponta a dignidade como uma maneira de fixá-la). (WALDRON, 2013b, p.03).

${ }^{10} \mathrm{O}$ exemplo aqui é da dignidade da posição ou função de juiz; a norma que criminaliza o desacato ao juiz não abarca toda a proteção ao status jurídico (à dignidade) do juiz, mas, juntamente com outras estipulaçōes, pode ser indispensável para proteção da dignidade judicial (WALDRON, 2012a, p.18).
} 
Há casos, diz Waldron (2013b, p.03), em que a linguagem dos documentos internacionais parecem considerar a dignidade como conteúdo de certos (não todos) direitos. Seria o caso do art. 10.1 do Pacto Internacional sobre Direitos Civis e Políticos: "Toda pessoa privada de sua liberdade deverá ser tratada com humanidade e respeito à dignidade inerente à pessoa humana” [grifo nosso]. E o Autor problematiza: será que essa dignidade seria, como querem alguns, diferente daquela proclamada no art. 13.1 do Pacto Internacional "Os Estados Partes do presente Pacto [...] [c]oncordam em que a educação deverá visar ao pleno desenvolvimento da personalidade humana e do sentido de sua dignidade [...]" [grifo nosso]? Waldron pensa que não. A dignidade pode aparecer sob as mais diferentes roupagens, de forma mais ou menos direta, e ter mesmo diferentes funções em se tratando de direitos diversos.

Eis exemplos: para Waldron (2013b, p.04), algumas normas estabelecem o status jurídico geral, enquanto outras normas particulares protegem esse status de forma afirmativa, estabelecendo condições concretas que devem ser promovidas pelo Direito (e.g., direito a uma remuneração conforme à dignidade humana), ou de forma negativa, como as proibições de tratamento degradante ou humilhante. Não seria possível, em todo caso, saber de antemão qual o conteúdo da dignidade.

Nessa esteira, muito embora as proibições ao tratamento humilhante e degradante talvez pudessem ser consideradas por seu valor específico -- e não como acessórias à defesa mais ampla de uma posição ou status de dignidade humana -- ainda assim subsistiria a questão de "o que" a norma pretende quando trata de forma mais geral sobre a dignidade da pessoa humana. Daí a importância do esforço empreendido no artigo de Waldron: produzir uma teoria que unifique o que dizemos sobre dignidade no geral (como status normativo) e no específico (como normas particulares afirmativas ou negativas). (WALDRON, 2012a, p.18-9).

De acordo com Waldron (2013b, p.04-6), a premissa de que dificilmente os direitos derivam de um fundamento único (seja ele dignidade, igualdade, autonomia etc.) não autoriza negligenciar a possibilidade de a dignidade ser considerada um fundamento, especialmente no caso dos direitos humanos, que, notoriamente, são apresentados na forma de um rol de direitos e não como uma teoria unificada. Uma alternativa seria ponderar sobre direitos humanos a partir de uma abordagem mais pluralista, que leve em consideração que no rol de direitos humanos existem diversos tipos de direitos, portanto, também existem diversos fundamentos para estes direitos. O fato de a dignidade ser um fundamento importante, diz Waldron, não a coloca como um valor superior que elimina a possibilidade de existirem outros valores que também ocupam a posição de fundamento, relativamente a este rol de direitos. Para ele, o que faz um direito ser considerado "humano" é sua caracterização como um direito que, baseado em algum fato sobre a natureza humana, é atribuído a todos os seres humanos.

Assim, a natureza multifacetada dos direitos humanos, na visão de Waldron (2013b, p.06-7), não exige como fundamento uma única teoria sobre a humanidade. Além disso, a própria dificuldade de definição da 
expressão "dignidade humana” seria um obstáculo, já que seu significado é demasiadamente vago. Entretanto, diz o Autor que a vagueza não é necessariamente um sinal de descuido; ela pode evidenciar a intenção de não transmitir qualquer significado particular, ou pode ser um sinal de que estamos nos estágios iniciais na elaboração do conceito: a compreensão do seu significado é um trabalho em andamento. Sua ponderação, nesse caso, é de que sequer chegamos a um consenso sobre o que significa dizer que um determinado direito é um direito humano, ou quais são esses direitos; portanto, seria um exagero esperar um consenso sobre o fundamento destes direitos.

Ademais, a dignidade, argumenta Waldron (2013b, p.08-11), é um conceito bastante contestado, com concepções razoavelmente determinadas, bem cristalizadas, mas opostos umas às outras, manifestas não apenas no excesso de usos do termo "dignidade", mas por uma proliferação, especialmente na Filosofia Política, de uma série de teorias da dignidade. ${ }^{11}$ Ocorre que essa não é, lembra Waldron, a primeira vez que uma ideia fundamental da Teoria Política é apresentada como um "conceito contestado". ${ }^{12}$ Conceitos como liberdade, democracia e igualdade foram amplamente contestados mormente porque o fato de considerarmos estes valores como fundamentais provoca discussão sobre como eles devem ser concebidos e interpretados. Daí também a profunda relação entre dignidade e direitos humanos: a contestação sobre o seu significado tem crescido desde que as pessoas começaram a levar a sério as reivindicações apresentados nos preâmbulos das grandes cartas de direitos humanos. É justamente por essas declarações e pactos de direitos humanos fazerem diversas afirmações sobre o papel da dignidade que elas precisam ser compreendidas, a fim de determinar se, de fato, existe uma ligação fundamental entre a dignidade e os direitos humanos.

Explorar a ideia da dignidade humana como um fundamento, diz Waldron (2013b, p.12), importa, inicialmente, determinar o que significa ser um fundamento. Dentre as muitas possibilidades de compreender um fundamento, o Autor explora quatro justificativas daquilo pode significar dizer que determinado conceito ( $\alpha=$ dignidade) é o fundamento de outro conceito ( $\beta=$ direitos humanos):

i. Por uma questão de história e de genealogia, $\beta$ foi gerado a partir de $\alpha$;

ii. $\quad$ a é a fonte de $\beta$, no sentido de que a aplicação de um pode ser a fonte de validade do outro;

iii. $\quad \beta$ pode ser logicamente ou dedutivamente derivado de $\alpha$; ou

\footnotetext{
${ }^{11}$ Exemplificativamente, Waldron (2013b, p.08) cita a teoria kantiana baseada na capacidade moral autônoma, a teoria católica baseada na compreensão dos seres humanos como criados à imagem de Deus, a teoria da dignidade desenvolvida por Ronald Dworkin na obra "Justiça para ouriços", além da sua própria teoria sobre a dignidade como um status ao invés de um valor.

${ }^{12}$ Waldron (2014, p.12) lança mão, aqui e em vários outros escritos, do artigo de W. B. Gallie ("Essentially Contested Concepts". Proceedings of the Aristotelian Society, vol. 56, 1956) para elucidar que a contestação entre teorias e conceitos rivais pode ser produtiva. O referido trabalho cita a democracia como um caso paradigmático de conceito essencialmente contestado e indica a possiblidade de que uma forma de progredir na compreensão do conceito é justamente observar e participar na contestação das concepções rivais, para assim produzir um sentido mais rico dos conteúdo dos conceitos em questão.
} 
iv. a lança alguma luz indispensável em $\beta$ ou ajuda na interpretação de $\beta$.

A partir do uso da justificativa (i) o Autor afirma que a é fundamento de $\beta$, no sentido de que o discurso dos direitos humanos cresceu a partir de um discurso pré-existente sobre a dignidade humana. Ou seja, falar sobre a dignidade da pessoa humana ajudaria a explicar, de uma forma histórica, de onde vieram nossas ideias sobre direitos humanos. Para Waldron, antes do surgimento da linguagem de direitos humanos em sua forma moderna houve certamente um discurso pré-existente da dignidade humana, mas disso só se pode concluir que o discurso existente sobre a dignidade teve algum efeito no surgimento do discurso dos direitos humanos. Waldron argumenta que seria errado, no entanto, tratar o primeiro (dignidade) como o precursor histórico do último (direitos humanos), mormente porque, muito do que se diz sobre dignidade decorre justamente do discurso dos direitos humanos, surgido a partir de 1948, com o advento da Declaração Universal dos Direitos Humanos (WALDRON, 2013b, p.13-4).

Aplicando a justificativa (ii) seria possível afirmar que $\alpha$ é fundamento de $\beta$, no sentido de considerar a dignidade como o valor mais alto do sistema jurídico, portanto, seria a fonte de validade jurídica e, consequentemente, fonte de legitimidade das normas de direitos humanos. A invocação da dignidade humana pelos pactos internacionais de direitos humanos seria, nesse sentido, uma referência à natureza especial dos seres humanos e ao seu valor inerente, o que legitimaria a persecução dos direitos humanos antes (e independentemente) de sua positivação. Isso corresponderia, acresce Waldron, a uma explicação suprapositiva do motivo pelo qual damos importância para os direitos humanos e insistimos na sua universalidade, inalienabilidade, e irrenunciabilidade. Entretanto, para Waldron, seria mais plausível considerar que os pactos e declarações de direitos humanos representam, em si mesmos, respostas do Direito positivo para ideias suprapositivas, em vez de considerar que a legitimidade ou a validade das normas de direitos humanos pode ser encontrada no direito não positivado (WALDRON, 2013b, p.14-6).

A justificativa (iii) parece, diz Waldron (2013b, p.16-7), mais promissora, pois traz a possibilidade de que afirmar que $\alpha$ é fundamento de $\beta$, no sentido de que sabendo qual é o fundamento dos direitos podemos gerar ou derivar reivindicações de direitos humanos. Além de mais rigorosa do que uma mera lista de direitos dados, esta justificativa permitiria avaliar o que as pessoas dizem sobre os direitos humanos, o que dizem sobre quais são os direitos que temos, ou sobre o que (não) são direitos humanos. Mesmo nesta justificativa persistiriam problemas, pois pequenas variações conceituais na forma como o fundamento é especificado (por variações na própria concepção do conceito de dignidade) poderia levar a significativas diferenças nas reivindicações sobre os direitos que são gerados, derivados ou avaliados por este método. A delimitação do conceito, nesse contexto, poderia ser formulada de modo a amparar determinados tipos de reivindicações de direitos, enquanto antagonistas destes 
direitos acusariam seus teóricos de fazer isso; consequentemente, deve-se ter presente, afirma o Autor, que essa abordagem não alivia o fardo da defesa de determinadas reivindicações sobre direitos humanos.

Para Waldron (2013b, p.19-20), a justificativa (iv) é mais indutiva que a (iii). Sua utilização permitiria afirmar que $\alpha$ é fundamento de $\beta$, no sentido de que a compreensão dos direitos que temos depende da compreensão de alguns pressupostos que dão coerência a esses direitos. $O$ fundamento é o valor que auxilia a dar sentido ao rol de direitos, sem, necessariamente, ampliar a lista, acrescentando mais e mais direitos, como ocorreria na utilização da justificativa (iii). Isso porque o simples fato de esses direitos serem direitos jurídicos (legal rights) -- seja por sua previsão no Direito Constitucional, seja por sua previsão no Direito Internacional dos Direitos Humanos -- não elimina a necessidade de compreensão do fundamento, do conceito que auxilia na interpretação das disposições de direitos particulares, na determinação de como devemos proceder na promoção das reinvindicações baseadas em direitos, na maneira como devemos lidar com possíveis conflitos de direitos ou na questão de sua limitação.

Por fim, Waldron (2013b, p.28) alerta que considerar a dignidade como fundamento dos direitos humanos pode dar uma impressão equivocada de que a dignidade é um valor irredutível, que profundamente alicerça os direitos reconhecidos nas cartas de direitos humanos, de modo que, "uma vez que escavamos até à dignidade, não precisamos ir mais longe". Contudo, se não há consenso sobre o que seja a dignidade, e se cada teoria sobre seu conteúdo não nos conduz a uma concepção clara, mas sim a questões e controvérsias sobre essa ideia, talvez as respostas não possam ser encontradas no próprio fundamento (dignidade). Por isso, para Waldron, considerar a dignidade como um fundamento não exclui a possibilidade de que a própria dignidade necessite de um fundamento, de um valor maior ou ainda mais profundo que oriente sua aplicação ou do qual a dignidade possa ser derivada.

A dignidade, antes considerada como status (item 1 supra) expressava a noção de abreviação de uma lista de direitos, não no sentido de que temos direitos humanos porque temos a dignidade humana, mas no sentido de que possuir dignidade humana é o mesmo que possuir direitos humanos. Essa noção de dignidade como status, contudo, não fica limitada a expressar a simplificação de uma lista maior de direitos; ela expressa uma ideia subjacente que também explica a importância de cada um destes direitos em relação à condição humana, unificando-os. Para criticar a alegação de que a dignidade é um fundamento dos direitos, afirma Waldron, não basta dizer que tudo o que a dignidade faz é abreviar um conjunto de direitos, especialmente porque tal ideia de dignidade exige uma análise jurídica técnica que nem sempre corresponde ao sentido em que a dignidade é utilizada, por exemplo, por filósofos morais em preâmbulos de declarações de direitos humanos. Quando se compreende que a análise técnica não revela qualquer objeção insuperável para falar da dignidade (o status) como um fundamento para os direitos, fica mais fácil compreender que essas considerações não tem intenção de refutar vol. 08, nº. 04, Número Especial. Rio de Janeiro, 2015. pp. 2341-2360 


\section{Quaestio Iuris}

a afirmação de que os direitos humanos são fundamentados na dignidade humana. A intenção, segundo o Autor, é explorar essa justificação a fim de evidenciar os obstáculos que pode enfrentar, reforçando, assim, a reivindicação sobre a relação entre dignidade e direitos, já que muitas vezes é feita com teor meramente retórico (WALDRON, 2013b, p.25-7 e 29).

\section{A PROTEÇÃO DA DIGNIDADE PELO DIREITO}

Sopesando as considerações de Waldron até o momento, parece-nos que as diferentes formas de considerar a dignidade (como status ou como um possível fundamento dos direitos humanos) não são excludentes. Assim, mesmo invocando a proteção ou promoção dos direitos humanos, não se pode afirmar que exista um descolamento ou ruptura entre a noção moderna e igualitária de dignidade humana, com a noção antiga de função cívica e/ou posição hierárquica. Em vez disso, Waldron parece indicar que o que em realidade existe é a equalização de um tratamento de modo atribuir a todos -- e a cada ser humano -- algo da dignidade e de expectativa de respeito que antes era concedido apenas à nobreza. É isso, também, que Waldron (2012b, p.213) tenta demonstrar na relação que apresenta entre a dignidade e as Instituições, os procedimentos e as práticas características do Direito.

A proibição do tratamento degradante ou humilhante, a proibição do discurso de ódio e a proibição de discriminação injusta de qualquer tipo são, na visão de Waldron, formas pelas quais o Direito tenta proteger a dignidade dos indivíduos. Mas, no mais das vezes, também são formas contingentes que dependem elaborações legislativas ou judiciais para proteção da dignidade. Ao abordar a questão da proteção da dignidade pelo direito, Waldron procura demonstrar a existência de uma proteção menos precária e mais intimamente conectada com a própria natureza do Direito. É uma espécie de dignidade que, segundo o Autor, não depende de previsão específica ou explícita pelo ordenamento jurídico, e que mesmo assim é menos contingente, porque presente na própria forma e estrutura pela qual o Direito reconhece a dignidade do detentor de direitos. Noutras palavras: o sistema jurídico reconhece o indivíduo como apto a controlar e regular sua conduta a partir de sua própria compreensão das normas jurídicas, aplicando-as a seu modo, e sendo respeitado e considerado pela forma que as aplica. Segundo Waldron, do reconhecimento e respeito dispensados aos indivíduos como detentores de direitos (right-bearers) decorrem características muito particulares do sistema jurídico, das quais dependem o seu funcionamento (WALDRON, 2012a, p.49-51; 2012b, p.200-3).

\section{A proteção presumida na estrutura do sistema}


Para Waldron (2012a, p.51-3; 2012b, p.204-8), a autoaplicação das normas oficialmente promulgadas, independentemente de ação coercitiva do Estado, é uma destas características. O Direito sempre visa à autoaplicação, e isso evidencia o reconhecimento da dignidade do detentor de direitos, uma vez que representa a confiança no agir dos indivíduos, na sua capacidade para compreensão prática, na autodeterminação e na modulação do comportamento, relativamente às normas jurídicas. A dignidade, nesse contexto, não está presente apenas na obediência mecânica às normas jurídicas, já que muitas normas dependem de pensamento genuíno para captação da determinação e sua operacionalização (e.g. reduzir para velocidade razoável em caso de neblina), exigindo que o indivíduo reconheça a norma, apreenda a influência desta sobre sua conduta, delibere e aja de acordo com esse entendimento.

Como dito, mesmo normas indeterminadas podem ser autoaplicáveis. No entanto, em alguns casos, a autoaplicação não é possível ou desejável, seja por haver disputa sobre o direito e/ou sobre a aplicação da norma, seja por requerer uma determinação oficial quanto ao seu significado. Este é outro modo pelo qual o Direito inerentemente protege a dignidade: permitindo que o detentor de direitos compareça perante um tribunal demandando ser ouvido, e que a sua visão seja considerada antes de qualquer decisão pública (WALDRON, 2012a, p.54-5; 2012b, p.206).

Os Tribunais e seus procedimentos, nessa esteira, representam elementos essenciais ao invés de um mero aspecto incidental do Estado de Direito. Mormente porque o funcionamento de um Tribunal envolve um modo de proceder que oferece imparcialidade e igualdade de oportunidades de manifestação e expressão de suas observações, assim como da compreensão particular do conteúdo da norma. Todo o procedimento é estipulado com intuito de que ambos os lados sejam tratados com respeito e, sobretudo, ouvidos sobre sua visão e perspectiva quanto à aplicação da norma à sua conduta ou situação. As formalidades intrínsecas ao procedimento do Tribunal envolvem uma noção intimamente ligada à dignidade, de consideração daqueles que são sujeitos às normas jurídicas, como "seres capazes de explicar a si mesmos" (WALDRON, 2012a, p.54; 2012b, p.208-10).

Isso faz com que o reconhecimento da dignidade pelo Direito não esteja presente apenas, sustenta Waldron (2012a, p.52-3; 2012b, p.210-2), no procedimento do Tribunal ou no direito da parte de se fazer ouvir no processo, mas também na própria argumentação jurídica. Construir o significado do seu direito dentro do sistema de modo que o direito adquira uma estrutura que intelectualmente faça sentido é, diz Waldron, outra vertente do respeito do direito à dignidade humana, pois com isso o Direito reconhece aqueles que estão subordinados a ele como portadores de razão e inteligência. Não se trata de uma incoerência com a primeira vertente apresentada (da autoaplicação das normas jurídicas), mas do reconhecimento que nem sempre o Direito pode ser completamente determinado. Para Waldron, trata-se de um ato de fé na razão prática e na capacidade de deliberação das pessoas comuns, assim como em sua capacidade de aplicar predicados morais gerais (como no 


\section{Quaestio Iuris}

exemplo anterior, determinar o significado de razoável), ponderando e interpretando todo um conjunto de normas.

Waldron (2012a, p.60-1; 2012b, p.215-6) destaca que tanto o direito de apresentar-se diante de um Tribunal quanto o direito de argumentar são construções fictícias, uma vez que a maioria das pessoas comuns não conseguiria desempenhar tais funções com a desenvoltura necessária à defesa de seus direitos, sem o conhecimento técnico específico. Por isso o Direito utiliza o artifício da representação jurídica como técnica de construção da igualdade necessária ao exercício deste direito. ${ }^{13}$ Mas isso, afirma Waldron, nada mais é do que o próprio comprometimento do direito com a generalização da dignidade, uma forma de lidar com as desigualdades entre as pessoas, por meio de práticas e técnicas que recriem uma igualdade perante a lei.

Por outro lado, o caráter coercitivo do Direito pode, à primeira vista, parecer incoerente com a argumentação apresentada, já que o Direito, por característica e natureza, é um instrumento de controle social. Waldron não tenta minimizar esta faceta do Direito, dado que não acredita ser necessário escolhermos entre as definições do Direito que enfatizam a coerção e aquelas que enfatizam considerações com a dignidade. Para tanto, o Autor oferece alguns argumentos. Um argumento mais genérico é a premissa segundo a qual o exercício do poder inerente ao Direito é canalizado por meio de processos e procedimentos, de modo que, quanto mais violenta e coercitiva a consequência prevista pelo Direito, mais complexo e formal é o processo e a instituição que o aplica, tornando mais difícil o exercício do poder. Para Waldron, certamente, esta é uma evidência da preocupação do Direito com a dignidade, no contexto do Estado de Direito (WALDRON, 2012a, p.62; 2012b, p.216-7).

Mas este argumento genérico não é a única forma de demonstrar a inexistência da suposta incoerência acima referida. Waldron (2012a, p.62-4; 2012b, p.217-9) utiliza outros quatro argumentos mais específicos para demostrar que mesmo o caráter essencialmente coercitivo do Direito é utilizado com respeito à dignidade:

i. O Direito apresenta suas normas como demandas categóricas e inegociáveis; ainda assim, sempre visa à autoaplicação, evidenciando que a coerção apenas é alternativa quando não há cumprimento voluntário de sua determinação;

\footnotetext{
${ }^{13}$ A analogia feita por Waldron (2012a, p.20) remete aos escritos de Hannah Arendt (tanto na obra On Revolution, quanto na obra Between Past and Future: Eight Exercises in Political Thought, ambas publicadas pela Penguin Books em 1977). A comparação é com a narrativa da Autora sobre o compromisso político de igualdade entre homens livres (cidadãos) da Atenas antiga. Naquele tempo, a igualdade não fora adotada por nenhuma convicção moral sobre a real igualdade entre eles, mas porque era um princípio que tornava possível a forma de comunidade política que necessitavam e/ou queriam, mas que, por outros meios, não conseguiriam. Para esse empreendimento político, criaram uma persona artificial (cidadão) que se apresentava como igual para fins políticos, expressando essa igualdade por técnicas artificiais tais como: o direito de falar em assembleia, o direito à igualdade de votos etc.
} 
ii. A necessidade de utilização de meios coercitivos não pressupõe -- sequer autoriza -- a utilização de meios degradantes ou humilhantes;

iii. Mesmo casos extremos de aplicação de penas severas, como a pena de morte, são estabelecidos procedimentos cujo intuito é preservar a humanidade até o momento da extinção da vida; e por fim,

iv. Sequer o fato de manter o indivíduo sob custódia autoriza o uso da força, pois existe uma presunção de autocontrole e de obediência, característicos da dignidade, que mesmo nesta circunstância deve ser mantido. Todos esses argumentos reforçam a ideia que até mesmo os meios pelos quais o Direito exerce o seu poder devem proteger a dignidade.

O caráter essencialmente coercitivo do Direito não pode ser confundido com um compromisso com a brutalidade, o terror, ou mesmo uma intenção de destruir a humanidade e a capacidade de agir de seus sujeitos. Para Waldron, o poder de coerção do Direito não autoriza o mesmo Direito a infligir penas insuportáveis, que subjuguem física ou psiquicamente as características humanas, ${ }^{14}$ pois isso implicaria na diminuição da posição ou do status daquele portador de direitos. A proteção da dignidade no caráter coercitivo do Direito está presente, portanto, a fim de que, havendo necessidade de punição, ela seja equivalente àquela atribuída a um nobre, e não à atribuída a um escravo (WALDRON, 2012a, p.62-4).

\section{A insuficiência de proteção concreta}

Neste último ponto, relativamente o caráter coercitivo do Direito, Waldron (2012a, p.64; 2012b, p.220) traz à tona a questão da proteção presumida pela estrutura do sistema jurídico versus a proteção concreta da dignidade humana. A dignidade, considerada normativamente, representa tanto uma aspiração quanto uma censura às deficiências do sistema. Nesse sentido, Waldron demonstra que a proteção concreta conferida à dignidade humana em muitos sistemas jurídicos fica aquém da proteção almejada. Segundo o Autor, tal situação pode ser verificada especialmente diante da necessidade dos sistemas jurídicos de lidar com o fardo de sua própria história, assim com os vestígios de compromissos ideológicos com uma dignidade que privilegia o status-classe; ou seja, sistemas jurídicos que categorizam sujeitos com base na classe de pessoas, submetendo-os a tratamentos reservados aos status inferiores (como escravidão ou servidão).

\footnotetext{
${ }^{14}$ Aqui não se trata apenas das questões relacionadas à tortura, mas de que o indivíduo seja capaz de suportar a pena sem precis ar abandonar seu caráter humano fundamental. Para Waldron, essa ideia remete à concepção antiga de dignidade no sentido de que seu alto caráter também tem conotações físicas, algo que ele chama de "ortopedia moral da dignidade humana", que remetem às noções de postura de nobreza, ao "caminhar ereto"; assim quando ouvimos a afirmação de que "alguém tem dignidade", o que vem a mente são imagens relacionadas com a presença do indivíduo, de sua posição de integridade e de autocontrole, e não alguém demasiadamente submisso em situações de adversidade (WALDRON, 2012a, p.21-2; 2012b, p.219).
} 
A narrativa apresentada por Waldron traz os Estados Unidos como exemplo, com toda sua história de escravidão e racismo institucionalizado. Historicamente, mesmo quando a 13a Emenda aboliu a escravatura, ela não o fez incondicionalmente, mas fez uma exceção explícita para o tratamento de prisioneiros: "Não haverá, nos Estados Unidos ou em qualquer lugar sujeito a sua jurisdição, nem escravidão, nem trabalhos forçados, salvo como punição por um crime pelo qual o réu tenha sido devidamente condenado" (WALDRON, 2012a, p.65, grifo nosso).

Mas não é apenas na história que se manifesta a insuficiência de proteção concreta da dignidade. Waldron (2012a, p.64-6; 2012b, p.220-1) descreve a existência de relatos bastante recentes de que nos Estados Unidos muitas vezes os réus são mantidos calmos e em silêncio nos tribunais americanos pelo uso de tecnologia que permite ao juiz submetê-los a choques elétricos em caso de mau comportamento; descreve também outros relatos de presos sendo "arrebanhados" com cassetetes elétricos. Waldron sustenta, ainda, que o uso da pena de morte poderia até mesmo representar um resíduo de selvageria do sistema norte-americano, além de falta de aderência deste sistema com a dignidade humana na forma por ele defendida. Afora isso, talvez o caso mais flagrante, na opinião de Waldron, seja o da detenção ilegal e dos casos de torturas ocorridos na Baía de Guantánamo. E apesar do exemplo central ser os Estados Unidos, casos e mais casos da insuficiência de proteção da dignidade poderiam ser identificados em outros países, tais como França, Reino Unido, Rússia, Israel e outros, que, mesmo sob circunstâncias diferentes, ficariam aquém da proteção nos termos apresentados por Waldron.

Segundo o Autor, devemos ter em mente que os sistemas jurídicos são ordens normativas, tanto explicita quanto implicitamente. A ordem normativa explícita contida nos sistemas jurídicos expressa um compromisso público, e como tal é de fácil percepção e demonstração quando a proteção concreta fica aquém da proteção almejada. Para Waldron, menos simples é o caso do compromisso normativo incorporado implicitamente nas instituições ou tradições de um sistema jurídico (item 3.1 supra). Esse compromisso implícito pode ser pensado como sendo inerente ao sistema, mesmo que a proteção concreta, algumas vezes, fique aquém disso. As práticas, diz Waldron, às vezes transmitem uma espécie de promessa, e o Direito pode, de forma crível, assegurar um respeito pela dignidade e ainda trair essa promessa em vários aspectos. Também as instituições podem ser imbuídas em suas estruturas e procedimentos com valores e princípios que às vezes ficam aquém da proteção almejada (WALDRON, 2012a, p.62-6; 2012b, p.221).

Aqui, é importante lembrar, refere Waldron (2013b, p.05-6), que dignidade (explicitamente) não figura na Constituição dos Estados Unidos, sendo apenas invocada esporadicamente pela doutrina constitucional. E mesmo essa invocação acaba sendo bastante limitada, envolvendo, e.g., questões relativas à punição cruel e incomum, ou algumas vezes, tendenciosamente, incorporando a própria liberdade e o direito de defesa do cidadão em relação ao Estado. Mas, para Waldron (2012b, p.221-2), mesmo assim, o compromisso do Direito com a vol. 08, nº. 04, Número Especial. Rio de Janeiro, 2015. pp. 2341-2360 


\section{Quaestio Iuris}

dignidade está incorporado institucionalmente nas duas formas descritas: tanto na ordem normativa explícita, quanto na ordem normativa implícita. No mais das vezes, não é necessário uma regra explícita de direito positivo para perceber a proteção da dignidade pelo Direito, mas, estando ela descrita no ordenamento jurídico, a sua proteção adquire um caráter mais robusto. Assim, estando a dignidade presente, tanto explicitamente (pactos e declarações internacionais), quanto implicitamente (nas práticas e procedimentos das instituições), esses compromissos reforçam-se mutuamente, e sua presença não permite que a dignidade seja tratada como algo que ou é completa e concretamente satisfeita, ou deve ser desconsiderada.

\section{Conclusão}

Os argumentos que Jeremy Waldron vem apresentando sob a dignidade têm sido fonte fértil de debates e críticas, ${ }^{15}$ para além de serem, como supomos ter ficado claro, audaciosas e contrárias aos lugares-comuns sobre o tema. ${ }^{16}$ A exposição acima pretendeu explicitar a acuidade analítica e a profundidade de abordagem com que o Autor vem tratando da matéria. Nestas considerações finais pretendemos contextualizar minimamente a temática no âmbito da Teoria do Direito e chamar a atenção para a singularidade do pensamento de Waldron, que vai na contracorrente do que se tem escrito sobre o tema.

As reflexões de Waldron sobre a dignidade são fieis tanto ao seu positivismo normativo ${ }^{17}$ quanto ao seu pluralismo. Esses fundamentos jusfilosóficos andam juntos e produzem consequências importantes para o conteúdo da dignidade proposta pelo Autor. Ao construir uma ideia conceitual de dignidade jurídica apartada o quanto possível da filosofia moral, Waldron evita tanto o relativismo que termina por desdenhar a dignidade e vêla como um conceito vazio quanto uma espécie de absolutismo que vê na dignidade o fundamento último dos direitos.

Ao mesmo tempo, ao buscar dar à dignidade um conteúdo próprio e independente do conteúdo moral (que a dignidade pode igualmente ter), Waldron é francamente positivista. A ideia-força é a de que o Direito tem independência em relação à moral, embora possa ser por ela influenciado e influenciá-la, e é justamente essa independência que Waldron busca destacar e com base nela construir um sentido jurídico à dignidade que tenha um mínimo de normatividade.

\footnotetext{
${ }^{15}$ Além das críticas expostas no livro que resultou das Berkeley Tanner Lectures, o leitor interessado encontrará dez artigos críticos no vol. 43 da Arizona State Law Journal, 2011, dedicado inteiramente ao artigo de Waldron intitulado Dignity, Rights, and Responsibilities, publicado no mesmo volume e citado neste artigo.

${ }^{16}$ É igualmente a posição de Meir Dan-Cohen, que presidiu as Berkeley Tanner Lectures e organizou o livro que as contém. Ver DAN-COHEN, Meir. Introduction: Dignity and Its (Dis)content. In: WALDRON, Jeremy. Dignity, Rights, and Rank (Berkeley Tanner Lectures). Oxford University Press, 2012.p.03-10.

${ }^{17}$ Ver WALDRON, Jeremy. Normative (or Ethical) Positivism. In: COLEMAN, Jules (Ed.). Hart's Postscript: Essays On The Postscript To The Concept Of Law. Oxford: Oxford University Press, 2001.p. 411-433.
} 
Ao mesmo tempo, o pluralismo de Waldron aparece de diversas formas: ele se recusa a entender a dignidade como o único e mais importante fundamento dos direitos humanos, e mesmo combate a ideia de que a dignidade possa operar somente como fundamento de algo (direitos humanos ou o que for). A dignidade pode operar tanto como valor (um dentre tantos) quanto como fundamento de alguns (não todos) direitos. Pode mesmo operar como (em linguagem continental) como "bem jurídico" a ser protegido ou mesmo a ser construído ou alcançado -- um status a ser perseguido e protegido pelo direito. É plural, portanto, o conteúdo da dignidade. Daí que é um erro, na visão de Waldron, emprestar à dignidade um conteúdo (meramente) "kantiano" ou católico ou dworkiniano ou outro qualquer a uma expressão que hoje se pretende universal.

Todas essas considerações contribuem para a constatação de que a dignidade é, essencialmente, um conceito contestado e, como tal, precisa ser mais bem elaborado pela Teoria do Direito. Também por isso é ela um conceito que merece ser analisado sob todas as suas funções, tanto fundamentais como explicativas, para que além da conceituação intuitiva, possamos construir algum significado de conteúdo jurídico. Waldron caminha assim na contracorrente do pensamento dominante, que busca entender a dignidade somente como fundamento de direitos, especialmente quando em referência a Direitos Humanos.

Noutras palavras, Waldron empreende um esforço interpretativo para construir, a partir do direito, um conteúdo normativo apto a dar sentido racionalmente rastreável às tantas e tantas positivações que a dignidade vem ganhando, seja em cartas e pactos internacionais, seja em constituições no plano do direito interno. Esse esforço em direção da normatividade da dignidade quer tanto contribuir para sua consolidação, quanto para dissipar eventuais confusões decorrentes de sua utilização como mera retórica. ${ }^{18}$

É interessante, porém, referir que parte do pensamento de Waldron não é original, como ele mesmo reconhece: referimo-nos à ideia de dignidade como status, que acompanha, no seu núcleo, os estudos do historiador do direito e Professor em Yale James Q. Whitman, talvez o precursor dessa visão nos Estados Unidos. ${ }^{19}$ Vai nesse sentido a consideração de que a igualdade não permite que seres humanos sejam distinguidos em relação ao seu valor; quando apoiada pela ideia de dignidade, a igualdade adquire um novo caráter: o de que não basta que os seres humanos sejam tratados igualmente, mas é indispensável que o patamar de igualação seja superior (leveling up). A dignidade, considerada como um status jurídico, expressa uma expectativa de tratamento de deferência e respeito que antes era reservado apenas aos portadores de nobreza ou importante função cívica,

\footnotetext{
${ }^{18} \mathrm{Um}$ dos autores deste ensaio empreendeu estudo das decisões do STF que utilizaram a dignidade em temas referentes ao direito administrativo. Ver GIACOMUZZI, José Guilherme. Dignidade Humana e Direito Administrativo no STF: uma breve análise crítica. Novos Estudos Jurídicos. v. 20, n. 2, 2015.

${ }^{19}$ Ver WHITMAN, James Q. Harsh Justice: Criminal Punishment and the Widening Divide between America and Europe. Oxford: Oxford University Press, 2003; e The Two Western Cultures of Privacy: Dignity Versus Liberty. Yale Law Journal, v. 113, p. 1151-1221, 2004.
} 
mas que "hoje" deve ser dispensado a todos os detentores de direitos. Dignificar os homens é tratá-lo como se todos fossem reis, e não súditos.

Já a ideia de Waldron de que há uma proteção à dignidade inerente ao próprio sistema jurídico parecenos original e iluminadora. Ao sustentar que a dignidade é um valor ou bem ou status que está muitas vezes implícito nas normas e instituições, Waldron parece querer reforçar a importância do caráter ético-normativo do direito, no sentido de que o respeito às práticas jurídico-processuais institucionalizadas ao longo dos tempos (como por exemplo a oitiva do outro e a consideração séria dos seus argumentos pelo juiz) buscam transmitir tanto um compromisso de tratamento digno ao detentor de direito quanto a confiança no modo em que se dará o exercício do direito por aquele que o detém. Se imaginarmos, como quer Waldron, que essa reciprocidade de tratamento garante o próprio funcionamento do sistema jurídico, e se entendermos que o respeito ao direito e suas instituições é uma forma de respeitar e elevar a dignidade de todos nós, talvez tenhamos dado um passo importante na tentativa de compreender que a dignidade é uma construção humana, obra conjunta e plural, e não algo dado a ser descoberto.

\section{DIGNITY IN JEREMY WALDRON'S WORK}

\section{Abstract}

This article describes the main ideas proposed by the political philosopher and legal theorist Jeremy Waldron about dignity, which is a subject central to human rights. The article is divided into three parts: the first part tackles the problem of dignity as status, which brings the notions of rank and role; the second part faces the problem of dignity as the foundation of rights; and the third part, which is subdivided into two, deals first with the various ways law protects dignity and later with the eventual failure of this very protection. Final considerations follow at the end.

Keywords: Jeremy Waldron. Dignity. Human Rights.

\section{REFERÊNCIAS BIBLIOGRÁFICAS}

SCHACHTER, Oscar. Human Dignity as a Normative Concept. American Journal of International Law. v. 77, p. 848-854, 1983.

WALDRON, Jeremy. Citizenship and Dignity. New York University School of Law, Public Law Research Paper No. 12-74, Jan. 2013a. Disponível em: http://ssrn.com/abstract=2196079. Acesso em: 07.12.2014.

Dignity, Rank, \& Rights (The Berkeley Tanner Lectures). Oxford: Oxford University Press, 2012a.

Dignity, Rights and Responsibilities. Arizona State Law Journal. Vol. 43, Issue 4, winter 201 1, pp. 1107-36.

How Law Protects Dignity. The Cambridge Law Journal. Vol. 71, Issue 01, Mar. 2012b, pp. 200-22.

Disponível em: doi:10.1017/S0008197312000256. 
Is Dignity the Foundation of Human Rights? New York University School of Law, Public Law Research Paper No. 12-73, Jan. 2013b. Disponível em: <http://ssrn.com/abstract=2196074>.

Normative (or Ethical) Positivism. In: COLEMAN, Jules (Ed.). Hart's Postscript: Essays On The Postscript To The Concept OfLaw, Oxford: Oxford University Press, 2001, p. 411-433.

What do the Philosophers Have against Dignity? New York University School Of Law Public Law \& Legal Theory Research Paper Series. Working Paper No. 14-59, Nov. 2014, Disponível em: $<$ http://ssrn.com/abstract=2497742>.

WHITMAN, James Q. Harsh Justice: Criminal Punishment and the Widening Divide between America and Europe. Oxford: Oxford University Press, 2003.

2004.

The Two Western Cultures of Privacy: Dignity Versus Liberty. Yale Law Journal, v. 113, p. 1151-1221,

Trabalho enviado em 25 de julho de 2015.

Aceito em 28 de setembro de 2015. 